\title{
Covid-19: Harshest restrictions are imposed on Greater Manchester after talks collapse
}

\section{Elisabeth Mahase}

The harshest level of current restrictions (tier 3 ) is set to be imposed on Greater Manchester, England, after a struggle between local leaders and the government.

On 20 October the prime minister, Boris Johnson, announced the restrictions, which will ban household mixing and close pubs and bars. More than 2000 cases of covid-19 were confirmed in Greater Manchester that day, and the area reported an infection rate of 399.4 in 100000.

Greater Manchester's mayor, Andy Burnham, along with other leaders from the local council, had opposed the government's push to implement more restrictive measures without also providing the requested financial support for the lowest paid members of society and businesses.

Burnham and his colleagues entered negotiations asking for €9om (€99.2m; \$117.5m) (£15m a month) to provide an $80 \%$ furlough scheme and $80 \%$ self-employment support until the end of financial year. They agreed to reduce that to $€ 65 \mathrm{~m}$, which they said was the minimum amount required to prevent poverty, hardship, and homelessness. The government offered Ł6om.

"How could I sign up to a deal that did not provide the basic level of support?” said Burnham. Responding to concerns that the government would then withdraw its €6om offer, he added, "Is this a game of poker? Are they playing poker with people's lives through a pandemic? Is that how they are running this country?”

\section{Critical care beds}

Later the same day in a press conference Johnson confirmed that the restrictions would come into effect on 23 October. He said, "I know that these restrictions are tough on individuals and businesses, and believe me, no one wants to be putting these things into effect."

He confirmed that Greater Manchester would receive $£ 22 \mathrm{~m}$ for contact tracing, adding that he wanted to "do more, but for the sake of fairness, the deal has to be in line with deals we have done with Lancashire and Merseyside.” These areas received $£ 42 \mathrm{~m}$ and $£ 44 \mathrm{~m}$, respectively.

Johnson was then repeatedly asked whether the £6om offer would still be fulfilled, but he failed to clarify the situation. England's health secretary, Matt Hancock, later told the House of Commons that the offer was still on the table.

Last week, while talks were ongoing between the government and Manchester's local leaders, a document leaked to the Guardian showed that Greater Manchester could soon run out of critical care beds owing to covid-19 and that some hospitals in the region were already full. ${ }^{1}$

In a letter to Johnson, ${ }^{2}$ Burnham suggested that the government had attempted to "raise public concern about the NHS in Greater Manchester with selective statistics." He argued that the occupancy rate in intensive care units was "not abnormal for this time of year and is comparable to the occupancy rate in October 2019. Also, providing information about individual hospitals does not reflect that our hospitals work as a system to manage demand."

A spokesperson for the Greater Manchester Health and Social Care Partnership told The BMJ, "This is a dynamic, changing situation, and our hospitals will vary their overall bed capacity, including intensive care units, to cope with demand, as well as working collaboratively to take care of patients. Therefore, the overall numbers and capacity in the system and in individual hospitals varies from day to day."

Further requests by The BMJ for details on the current capacity in Greater Manchester hospitals did not yield any results. The secrecy surrounding the data has been outlined by the Manchester Evening News. ${ }^{3}$

\section{Other regions}

However, case numbers are also rising elsewhere in England. In the UK, 21331 new confirmed cases of covid-19 were reported in the most recent 24 hour period. In England and Wales this was the 24 hours up to $5 \mathrm{pm}$ on 19 October; in Scotland and Northern Ireland, up to 9.30 am on 20 October. During those periods 241 covid-19 related deaths were recorded: 213 in England, 10 in Wales, 15 in Scotland, and three in Northern Ireland.

The UK government has so far avoided implementing a short national lockdown in England-known as a circuit breaker-despite leaders in Scotland, Northern Ireland, and Wales all doing so in their respective countries and despite the UK government's own Scientific Advisory Group for Emergencies recommending the move. ${ }^{4}$

The Welsh government announced on 19 October that it would enforce a short lockdown from 23 October to 9 November, telling people to stay at home and all non-essential shops to shut. Meanwhile, in Northern Ireland a four week lockdown is currently under way, and Scotland has tightened its national restrictions such that households cannot mix and pubs and restaurants are either closed or running limited hours, depending on their area.

\footnotetext{
Campbell D, Walker P. Covid: Greater Manchester running out of intensive care beds, leak reveals. Guardian 2020 Oct 18. https://www.theguardian.com/world/2020/oct/18/revealed-some-manchester-area-hospitals-already-full.
} 
2 Greater Manchester Combined Authority. Statement from Andy Burnham and Sir Richard Leese. 19 Oct 2020. https://www.greatermanchester-ca.gov.uk/news/statement-from-andy-burnhamand-sir-richard-leese/.

3 Williams J. The secrecy and spin surrounding Greater Manchester's hospital figures. Manchester Evening News 2020 Oct 19. https://www.manchestereveningnews.co.uk/news/greater-manchester-news/secrecy-spin-surrounding-greater-manchesters-19131905.

4 Mahase E. Covid-19: Experts recommend two week circuit break to reduce transmission in the UK. BMJ 2020;371:m4038. doi: 10.1136/bmj.m4038 pmid: 33067176

This article is made freely available for use in accordance with BMJ's website terms and conditions for the duration of the covid-19 pandemic or until otherwise determined by BMJ. You may use, download and print the article for any lawful, non-commercial purpose (including text and data mining) provided that all copyright notices and trade marks are retained. 